\title{
SOLOS COM MORFOLOGIA LATOSSÓLICA E CARÁTER CÂMBICO NA REGIÃO DE GOVERNADOR VALADARES, MÉDIO RIO DOCE, MINAS GERAIS: GÊNESE E MICROMORFOLOGIA ${ }^{(1)}$
}

\author{
Manoel Ricardo de Albuquerque Filho ${ }^{(2)}$, Cristine Corole Muggler ${ }^{(3)}$, \\ Carlos Ernesto G.R. Schaefer ${ }^{(3)}$, João Carlos $\mathrm{Ker}^{(3)}$ \& Flavia \\ Cristina dos Santos $^{(2)}$
}

\begin{abstract}
RESUMO
Nas regiões do Médio Vale do Rio Doce marcadas por fortes alterações secoúmidas sazonais do clima, coexistem Latossolos, Cambissolos e Argissolos, com maior fertilidade nos últimos. Observações gerais da região indicam Latossolos com certa reserva em minerais primários, conferindo-lhes caráter câmbico, bem como Cambissolos com morfologia latossólica. Neste trabalho, foram estudadas a gênese e características pedológicas de Latossolos, Cambissolos associados e um Argissolo, em duas toposseqüências na microbacia do córrego do Desidério, no Planalto Soerguido/maciço montanhoso do divisor Suaçui Pequeno/Corrente Grande, região noroeste do município de Governador Valadares. Além de características químicas e físicas de rotina, foram investigadas as feições micromorfológicas de seis perfis de solos em duas toposseqüências e feitos exames microquímicos por microscopia eletrônica (EDS) nos diversos tipos de minerais amostrados. Tanto os Latossolos quanto os Cambissolos mostraram microestrutura granular típica, com relação silte/argila abaixo do limite requerido para diferenciar Latossolos de Cambissolos. O processo de coluvionamento associado à encosta onde há afloramento de rochas enriquece os solos a jusante, conferindo características câmbicas. Mesmo nos Latossolos mais profundos ocorrem alguns grãos residuais de feldspato potássico e, principalmente, micas degradadas, indicando relativa reserva de $\mathrm{K}$ não-trocável nestes solos. Nos Cambissolos latossólicos estudados há diversidade mineralógica muito maior na fração grosseira, com a coexistência de minerais instáveis (biotita, anfibólio, feldspato) e minerais
\end{abstract}

\footnotetext{
(1) Trabalho extraído da Tese de Mestrado do primeiro autor. Recebido para publicação em setembro de 2005 e aprovado em agosto de 2007.

${ }^{(2)}$ Pesquisador da Embrapa Cerrados/UEP-TO. Av. Teotônio Segurado 101, Sul, Caixa Postal 96, CEP 77001-970 Palmas (TO). E-mails: mricardo@cpac.embrapa.br; flavia@cpac.embrapa.br

${ }^{(3)}$ Professor Adjunto, Departamento de Solos, Universidade Federal de Viçosa - UFV. Av. PH Rolfs s/n, CEP 36570-000 Viçosa (MG). E-mails: cmuggler@ufv.br; carlos.schaefer@ufv.br; jcker@ufv.br
} 


\begin{abstract}
resistentes (minerais de Ti, gibbsita), denotando a intensa pedoturbação atuando sobre o material coluvial proveniente de afloramentos de rochas a montante. As áreas de Cambissolos com morfologia latossólica são preferencialmente utilizadas com cultivos de subsistência, devido à maior fertilidade química e profundidade destes solos.
\end{abstract}

Termos de indexação: micromorfologia de solos tropicais, solos poligenéticos, solos do mar de morros.

\author{
SUMMARY: SOILS WITH LATOSOLIC MORPHOLOGY AND CAMBIC \\ PROPERTIES IN GOVERNADOR VALADARES, MIDDLE RIO \\ DOCE RIVER, MINAS GERAIS REGION, BRAZIL: GENESIS AND \\ MICROMORPHOLOGY
}

\begin{abstract}
In the middle Rio Doce Valley, with strong seasonal dry-wet alterations, Latosols, Cambisols and Argissols coexist, with greater chemical fertility in the latter. General regional observations indicate a certain mineral reserve in Latosols, which gives them a "cambic" character, as well a "Latosolic" morphology in the Cambisols. In this study, we analyzed the genesis and pedological characteristics of Latosols, associated Cambisols and an Argisol in two toposequences from the Desidério catchment, in the Upper Plateau of the Suaçui Pequeno/Corrente Grande watershed, in the NW of Governador Valadares. A microchemical EDS examination of various types of mineral grain and clay plasma showed that both Latosols and Cambisols have a typical microgranular structure, with a silt/clay ratio below the required limit for a differentiation of Latosols from Cambisols. This was attributed to the intense pedobiological mixture of little weathered rock fragments containing primary minerals and a pre-weathered, latosolic clay plasma. The colluviation process in slopes with rocky outcrop greatly enriches downslope soils, resulting in their "cambic" properties. Even deeper Latosols have some scattered residual grain of $K$-feldspar and mostly illites, suggesting a relatively high non-exchangeable K-reserve. In the studied latosolic Cambisols (Inceptsols), the mineralogical diversity of the coarse fraction is much higher. Unstable minerals (biotite, amphibole and feldspars) coexist with resistant minerals (titanium minerals and gibbsite), evidencing intense pedoturbation of the colluvial material originated from the rocky outcrops situated upslope. Areas of Cambisols with "Latosols" mineralogy are the preferred sites of low-input subsistence farming, due to higher chemical fertility and depth of the soils.
\end{abstract}

Index terms: mar-de-morros soils, polygenetic soils, tropical soil micromophology.

\section{INTRODUÇÃO}

Muitos solos tropicais são típicos por apresentarem profundidades excepcionais e por se desenvolverem sobre materiais de origem pré-intemperizados, conseqüência de uma longa história pedogeomorfológica (Stoops, 1989), com alternâncias climáticas e ecológicas significativas. A paisagem da região a noroeste de Governador Valadares, inserida no domínio das terras elevadas do leste atlântico brasileiro, guarda a influência das mudanças climáticas e de atividade tectônica cenozóica (Saadi, 1993; Souza, 1995), que modificaram a morfologia original associada ao profundo manto de intemperismo da Superfície Sul-Americana (King, 1956), hoje fragmentada e dissecada.

Essas áreas serranas, submetidas a um clima sazonal, de relevo forte ondulado e elevada densidade de drenagem, apresentam morfogênese freqüentemente mais intensa que a pedogênese (Ab'Saber, 1977; Resende et al., 1995). Localmente, nas microbacias da região, observam-se encostas dissecadas e ravinadas, com freqüentes afloramentos de rochas em meio ao manto latossólico, solos predominantemente pobres ao lado de solos com marcante influência do material de origem, com ocorrência de fragmentos de rochas em diferentes estádios de decomposição. Assim, nas porções onde o material de origem é rico em feldspato potássico e minerais máficos (hornblenda e biotita) (Brasil, 1970; CPRM, 2000), a presença desses fragmentos pode constituir uma reserva química de grande importância a médio e longo prazos.

A ocorrência de minerais facilmente intemperizáveis em solos de morfologia latossólica, conferindo-lhes caráter câmbico, tem sido esparsamente relatada em diversos estudos, em regiões com estação seca pronunciada (Brasil, 1970, 1981, 1983, 1987). A 
magnitude com que estes minerais podem influenciar as propriedades químicas do solo está diretamente relacionada à dinâmica de alteração dos grãos, bem como aos processos de bioturbação que determinam a interação do mineral com a matriz do solo. Estes processos são melhor compreendidos por meio de estudos micromorfológicos, que permitem a observação da estrutura, do grau de alteração dos grãos e do arranjo de partículas em microescala (Schaefer, 2001; Nunes et al., 2001).

Na região do Vale do Rio Doce, foram feitos estudos micromorfológicos (Embrapa 1977), que se limitaram às áreas de Argissolos, mais típicos da região, sendo necessário ampliar o leque de informações para outros solos de ocorrência regional. Assim, o objetivo deste trabalho foi estudar a gênese e as características micropedológicas de solos com morfologia latossólica e caráter câmbico na microbacia do Córrego do Desidério, localizada na área de maior amplitude altitudinal de Governador Valadares, em relação ao nível de base regional - o Rio Doce, a fim de fornecer subsídios ao entendimento da mineralogia e dinâmica de nutrientes desses solos.

\section{MATERIAL E MÉTODOS}

Foram caracterizadas duas toposseqüências similares situadas às duas margens do Córrego do Desidério, a noroeste de Governador Valadares, entre as coordenadas $-18^{0} 30^{\prime} \mathrm{W}$ e $-19^{\circ} 30^{\prime} \mathrm{W} /-41^{\circ} 30$ ' $\mathrm{Se}$ $-42^{\circ} 30$ ' S, numa região de clima Aw (Köppen, 1948), com inverno seco e chuvas concentradas no verão. Foram selecionados, descritos e coletados seis perfis de solos. Na toposseqüência 1, o perfil 1 foi descrito no topo do morro, sob mata; o perfil 2, na parte intermediária, sob bananal; e o perfil 3, em área de terraço, sob cultivo anual. Na toposseqüência 2 também foram selecionados três perfis (perfis 4, 5 e 6), referentes às mesmas posições da primeira. Os perfis foram descritos e coletados de acordo com Lemos \& Santos (1996).

As amostras foram destorroadas e passadas em peneira com malha de $2 \mathrm{~mm}$ de diâmetro, para obtenção de terra fina seca ao ar (TFSA). Foi realizada a caracterização física dos materiais de solos, determinando-se a textura, o teor de argila dispersa em água, o equivalente de umidade e o grau de floculação (Embrapa, 1979, 1997). As cores dos diferentes horizontes foram determinadas com base na caderneta de Munsell, a partir de amostras de TFSA secas e úmidas. Para caracterização química, foram feitas análises de $\mathrm{pH}$ em água e em $\mathrm{KCl}$; $\mathrm{Ca}^{2+}$, $\mathrm{Mg}^{2+}, \mathrm{K}^{+}, \mathrm{Na}^{+}, \mathrm{Al}^{3+}$, acidez potencial e $\mathrm{P}$ disponível (Embrapa, 1997), $\mathrm{P}$ remanescente (P-rem), após saturação da amostra por uma solução de $\mathrm{CaCl}_{2}$ $10 \mathrm{mmol} \mathrm{L}^{-1}$ com $60 \mathrm{mg} \mathrm{L}^{-1}$ de P (Alvarez V. et al., 2000) e C orgânico total (COT) (Yeomans \& Bremner, 1988). Além disso, os teores de $\mathrm{SiO}_{2}, \mathrm{Al}_{2} \mathrm{O}_{3}, \mathrm{Fe}_{2} \mathrm{O}_{3}$,
$\mathrm{TiO}_{2}, \mathrm{~K}_{2} \mathrm{O}, \mathrm{P}_{2} \mathrm{O}_{5}$ e micronutrientes ( $\mathrm{Mn}, \mathrm{Cu}$ e $\mathrm{Zn}$ ) foram determinados a partir do extrato obtido no ataque sulfúrico (Embrapa, 1997).

As formas cristalinas de $\mathrm{Fe}$ associadas à fração argila dos solos foram quantificadas em extratos obtidos de três extrações sucessivas com ditionitocitrato-bicarbonato de Na (DCB) (Mehra \& Jackson, 1960), e as de menor cristalinidade foram quantificadas nos extratos obtidos em extração única com oxalato ácido de amônio (Schwertmann, 1964). Após remoção do Fe livre (DCB), as amostras de argila foram montadas em lâminas orientadas por esfregaço (Embrapa, 1997) e irradiadas em difratômetro de raios X equipado com tubo de Fe e filtro de Co, para identificação dos argilominerais.

No estudo das feições micropedológicas foram utilizados termos de Fitzpatrick (1993), para microestrutura, e de Delvigne (1998), para as feições de alteração de grãos minerais presentes, cuja análise foi realizada em lâminas obtidas a partir de amostras indeformadas, coletadas em caixas plásticas com dimensões de 6 × $10 \mathrm{~cm}$, secas em estufa de circulação forçada a $38 \pm 2{ }^{\circ} \mathrm{C}$. No estado seco, as amostras foram impregnadas com resina de poliéster Polylite T208 dissolvida em monômero de estireno, na proporção 1,5:1, com utilização de peróxido de metil-etil-cetona como catalisador da polimerização, em ambiente ventilado. A polimerização deu-se após 10 dias, sendo então selecionadas fatias delgadas entre 2 e $4 \mathrm{~mm}$ de espessura, seguida do polimento de uma das faces em polidor com pó de carborundum e montagem em lâmina de vidro com araldite. Após montagem, procedeu-se ao desbaste até se atingir 30 micrômetros de espessura (Castro, 1985).

Secções finas selecionadas, previamente estudadas em microscópio petrográfico com polimento manual, foram preparadas para microanálise em microscopia eletrônica de varredura (MEV). Para isso, amostras de 2,0 x 2,5 cm foram polidas sucessivamente em disco de náilon com pasta de diamante, desde 60,6, 3 até $1 \mu \mathrm{m}$. Após lavagem final ultra-sônica para remoção de resíduos do polimento, as secções finas foram recobertas com filme condutor de $\mathrm{C}$ e montadas em suporte metálico. As lâminas foram subseqüentemente analisadas e fotografadas em microscópio eletrônico de varredura, modelo JEOL JSM 6400, com detector de retroespalhamento eletrônico acoplado ao espectrômetro de dispersão de raios X (PCXA-EDS), para exame microquímico das feições selecionadas. As análises microquímicas foram realizadas com voltagem de $15 \mathrm{kV}, 5 \mathrm{~A}$ e a $39 \mathrm{~mm}$ de distância de trabalho (detector-superfície). A cada troca de amostras, o PCXA-EDS foi recalibrado com padrão de cobre $(\mathrm{Cu}-$ $\mathrm{K} \alpha$ ). Essas análises foram realizadas no Centro Internacional de Microscopia e Microanálises da Universidade de Western Australia.

Após identificação de feições pedológicas com características químicas distintas, a partir de mapas dos elementos $\mathrm{Si}, \mathrm{Al}, \mathrm{Fe}, \mathrm{Ti}, \mathrm{Mn}, \mathrm{Ca}, \mathrm{Mg}$ e alguns 
microelementos, procedeu-se à análise dessas feições em magnificação elevada, obtendo-se espectros semiquantitativos por EDS. Todas as feições foram analisadas em três repetições, mapeadas e fotografadas em retroespalhamento eletrônico, para visualização da sua morfologia.

\section{RESULTADOS E DISCUSSÃO}

\section{Caracterização física e química}

Os solos possuem microestrutura granular típica dos Latossolos mais evoluídos (Lopes, 1984; Schaefer, 2001), textura média a argilosa, sendo mais argilosos aqueles das porções mais estáveis da paisagem (P1 e
P4), onde foram observados também os mais elevados graus de floculação (Quadro 1). Os demais solos apresentaram grau de floculação mais baixo que os dos perfis $\mathrm{P} 1$ e $\mathrm{P} 4$, porém a relação silte/argila (Quadro 1) situa-se abaixo dos limites estabelecidos para diferenciar Latossolos de Cambissolos (Embrapa, 1999). Mesmo nos solos com horizonte Bi (P2, P3 e P5) a relação manteve-se bem abaixo dos limites, em decorrência da mistura de materiais latolizados préintemperizados e fragmentos de rocha, coluviais.

Nas áreas livres da influência da rocha, ou seja, nos topos de morros (P1 e P4), os teores de $\mathrm{Ca}^{2+}, \mathrm{Mg}^{2+}$ e $\mathrm{P}$ são muito baixos, enquanto os de $\mathrm{K}^{+}$são médios e os de $\mathrm{H}+\mathrm{Al}$ elevados, indicando o estádio avançado de evolução desses solos (Quadro 2). Nas encostas dissecadas (P2 e P5) e nas rampas de colúvio (P3), os solos apresentaram altos valores de $\mathrm{pH}$ e teores mais

Quadro 1. Características físicas de solos da Microbacia do Córrego do Desidério

\begin{tabular}{|c|c|c|c|c|c|c|c|c|c|c|c|}
\hline \multirow{2}{*}{ Hor. } & \multirow{2}{*}{ Prof. } & \multicolumn{2}{|c|}{ Areia } & \multirow{2}{*}{ Silte } & \multirow{2}{*}{ Argila } & \multirow{2}{*}{$\operatorname{ADA}^{(1)}$} & \multirow{2}{*}{$\begin{array}{l}\text { Silte/ } \\
\text { argila }\end{array}$} & \multirow{2}{*}{$\begin{array}{c}\text { Grau de } \\
\text { flocul. }\end{array}$} & \multirow{2}{*}{$\begin{array}{c}\text { Equiv. de } \\
\text { umidade }\end{array}$} & \multicolumn{2}{|c|}{ Cor } \\
\hline & & Grossa & Fina & & & & & & & Seco & Úmido \\
\hline \multicolumn{4}{|c|}{$\mathrm{cm}$} & \multicolumn{3}{|c|}{ g $100 \mathrm{~g}^{-1}$} & \multicolumn{3}{|c|}{ 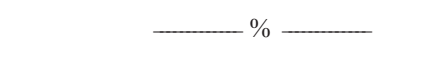 } & & \\
\hline \multicolumn{12}{|c|}{ P1 - Latossolo Vermelho-Amarelo típico (LVA) } \\
\hline A & $0-5$ & 56 & 8 & 11 & 25 & 6,58 & 0,46 & 73 & 16,6 & $7,5 \mathrm{YR} 5 / 4$ & $7,5 \mathrm{YR} 4 / 4$ \\
\hline A & $0-23$ & 51 & 8 & 7 & 34 & 7,71 & 0,21 & 77 & 16,9 & 7,5YR 5/6 & $5 \mathrm{YR} 3 / 4$ \\
\hline $\mathrm{Bw}$ & $100-110$ & 29 & 7 & 10 & 54 & 0,0 & 0,18 & 100 & 24,3 & $5 \mathrm{YR} 5 / 8$ & $5 \mathrm{YR} 4 / 6$ \\
\hline \multicolumn{12}{|c|}{ P2 - Cambissolo Háplico Tb distrófico argissólico (CXbd) } \\
\hline Ap & $0-5$ & 51 & 9 & 17 & 23 & 8,06 & 0,74 & 65 & 19,8 & 7,5YR 4/4 & $5 \mathrm{YR} 5 / 6$ \\
\hline $\mathrm{A}$ & $0-20$ & 43 & 12 & 22 & 23 & 5,61 & 0,96 & 76 & 20,1 & 7,5YR 3/4 & 10YR 3/2 \\
\hline $\mathrm{Bi}$ & $37-70$ & 39 & 10 & 9 & 42 & 9,18 & 0,21 & 78 & 24,5 & $5 \mathrm{YR} 3 / 4$ & $5 \mathrm{YR} 3 / 3$ \\
\hline $2 \mathrm{~A} / 2 \mathrm{Bi}_{1}$ & $85-100$ & 42 & 12 & 4 & 42 & 7,50 & 0,09 & 82 & 22,5 & $7,5 \mathrm{YR} 3 / 4$ & $7,5 \mathrm{YR} 3 / 2$ \\
\hline $2 \mathrm{Bi}_{2}$ & $114-134$ & 41 & 10 & 8 & 41 & 14,28 & 0,19 & 65 & 23,1 & 7,5YR 5/6 & $5 \mathrm{YR} 3 / 4$ \\
\hline \multicolumn{12}{|c|}{ P3 - Cambissolo Háplico Tb distrófico argissólico (CXbd) } \\
\hline Ap & $0-17$ & 58 & 10 & 14 & 18 & 2,55 & 0,82 & 85 & 19,4 & 10YR $3 / 3$ & 10YR 2/2 \\
\hline $\mathrm{AB}$ & $17-35$ & 71 & 10 & 6 & 14 & 3,73 & 0,46 & 71 & 18,0 & 7,5YR 4/6 & 7,5YR 3/4 \\
\hline $2 \mathrm{~A}$ & $35-44$ & 74 & 7 & 6 & 13 & 3,78 & 0,46 & 71 & 12,4 & 7,5YR 5/4 & 7,5YR $3 / 4$ \\
\hline $2 \mathrm{Bi}$ & $44-80^{+}$ & 48 & 13 & 11 & 28 & 10,05 & 0,39 & 64 & 16,7 & $7,5 \mathrm{YR} 4 / 6$ & $5 \mathrm{YR} 3 / 4$ \\
\hline \multicolumn{12}{|c|}{ P4 - Latossolo Vermelho-Amarelo distrófico típico (LVAd) } \\
\hline A & $0-20$ & 35 & 5 & 4 & 56 & 5,10 & 0,07 & 91 & 21,2 & $7,5 \mathrm{YR} 4 / 6$ & $7,5 \mathrm{YR} 3 / 4$ \\
\hline Bw & $90^{+}$ & 31 & 5 & 4 & 60 & 2,96 & 0,07 & 95 & 24,1 & 7,5YR 5/6 & $7,5 \mathrm{YR} 4 / 6$ \\
\hline \multicolumn{12}{|c|}{ P5 - Cambissolo Háplico Tb distrófico argissólico (CXbd) } \\
\hline A & $0-20$ & 51 & 10 & 13 & 26 & 9,34 & 0,52 & 63 & 27,3 & $7,5 \mathrm{YR} 5 / 4$ & $5 \mathrm{YR} 3 / 3$ \\
\hline $\mathrm{Bi}$ & $25-65$ & 39 & 14 & 16 & 31 & 33 & 0,52 & 74 & 23,7 & $5 \mathrm{YR} 6 / 6$ & $2,5 \mathrm{YR} 3 / 6$ \\
\hline CR & $160^{+}$ & 72 & 15 & 9 & 4 & 33 & 2,25 & 74 & 23,5 & $5 \mathrm{YR} 4 / 6$ & $5 \mathrm{YR} 3 / 4$ \\
\hline \multicolumn{12}{|c|}{ P6 - Argissolo Vermelho-Amarelo distrófico latossólico (PVAd) } \\
\hline $\mathrm{Ap}$ & $0-15$ & 38 & 10 & 18 & 34 & 36 & 0,54 & 55 & 24,6 & $7,5 \mathrm{YR} 5 / 4$ & $7,5 \mathrm{YR} 3 / 4$ \\
\hline $\mathrm{AB}$ & $15-25$ & 35 & 10 & 22 & 33 & 41 & 0,67 & 65 & 27,4 & 7,5YR 6/4 & $5 \mathrm{YR} 3 / 4$ \\
\hline $\mathrm{Bt}_{1}$ & $25-42$ & 39 & 8 & 18 & 35 & 15,87 & 0,53 & 53 & 26,8 & $5 \mathrm{YR} 6 / 6$ & $5 \mathrm{YR} 4 / 6$ \\
\hline $\mathrm{Bt}_{2}$ & $42-85$ & 36 & 10 & 17 & 37 & 0,51 & 0,47 & 99 & 28,2 & $5 \mathrm{YR} 6 / 6$ & $5 \mathrm{YR} 4 / 6$ \\
\hline $\mathrm{Bt}_{3}$ & $85-120$ & 28 & 12 & 19 & 41 & 0,50 & 0,46 & 99 & 31,6 & $5 \mathrm{YR} 6 / 6$ & $5 \mathrm{YR} 4 / 6$ \\
\hline $\mathrm{BC}$ & $120-150^{+}$ & 47 & 20 & 14 & 19 & 0,50 & 0,74 & 97 & 25,6 & 7,5YR 6/6 & $5 \mathrm{YR} 5 / 6$ \\
\hline
\end{tabular}

(1) Argila dispersa em água. 
Quadro 2. Características químicas de solos da Microbacia do Córrego do Desidério

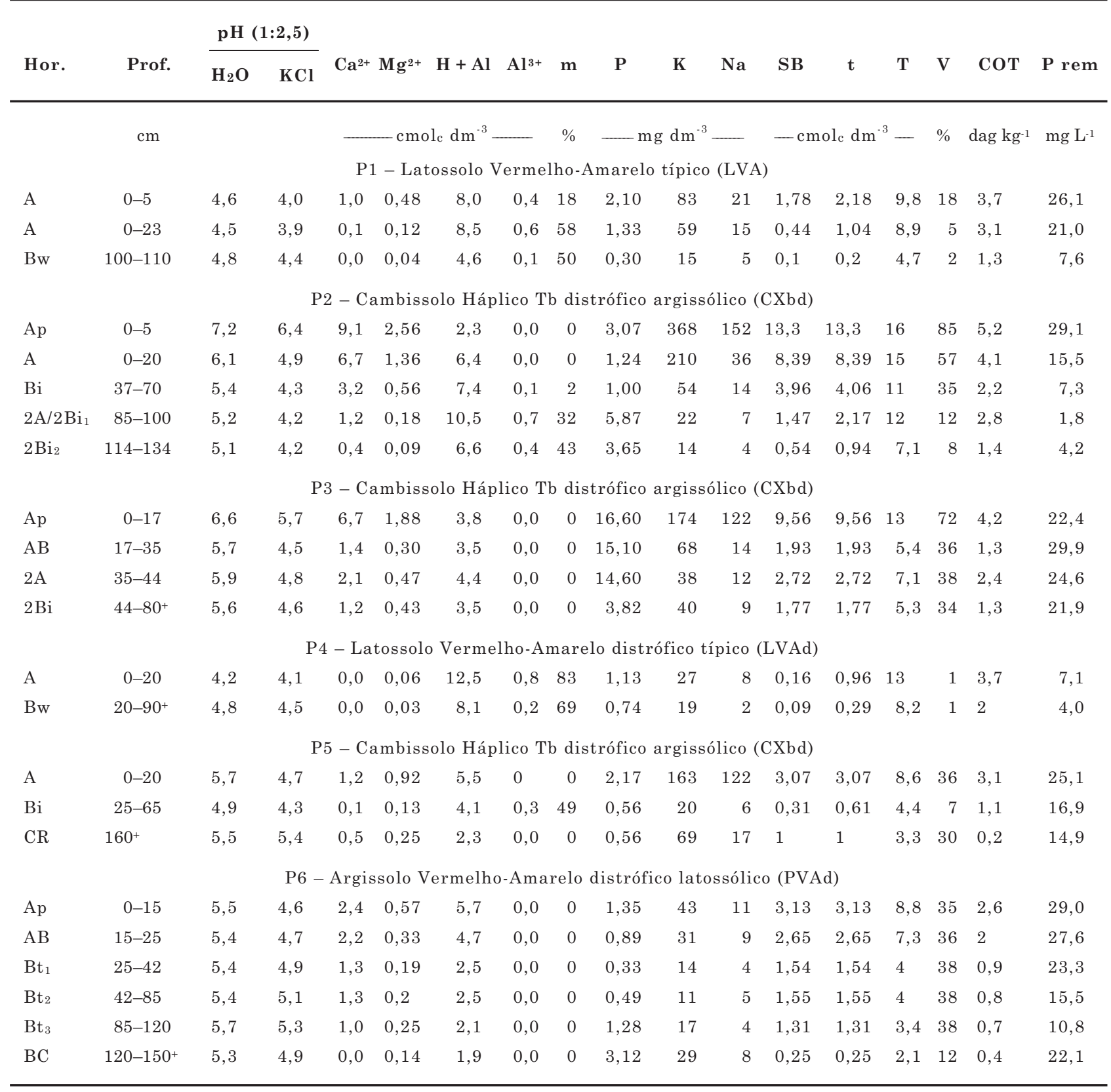

elevados de $\mathrm{Ca}^{2+}, \mathrm{Mg}^{2+}, \mathrm{K}^{+} \mathrm{e} \mathrm{Na}^{+}$até o horizonte Bi. A partir do horizonte $2 \mathrm{~A}$ (enterrado), há notável decréscimo nesses valores, indicando a ação da morfogênese atual, remobilizando colúvios enriquecidos pela presença de afloramentos de rocha a montante e conferindo aos solos características câmbicas. Por outro lado, os valores de Ki e Kr abaixo de 2 para todos os solos estudados, na faixa de solos gibbsíticos-oxídicos nas porções mais estáveis, associados aos valores de $\mathrm{Fe}_{\mathrm{o}} / \mathrm{Fe}_{\mathrm{d}}$ e à elevada proporção de gibbsita detectada pela difratometria de raios $\mathrm{X}$, corroboram a morfologia latossólica dos solos estudados, proporcionando valores de P-rem muito baixos nos horizontes $\mathrm{Bw}$ dos solos de posição mais elevada (P1 e P4). Nos solos em meia encosta, os teores de P-rem são elevados em superfície e baixos nos horizontes mais profundos, pela influência do material latossólico, enquanto nos terraços, com maior acumulação e possível ressilificação, os teores de Prem são mais elevados (Quadro 3).

Além dos afloramentos, as diferenças quanto à composição química da rocha aflorante influenciaram as propriedades químicas dos solos. Assim, a riqueza em minerais máficos do saprolito do perfil P5 
Quadro 3. Resultados de $\mathrm{SiO}_{2}, \mathrm{Al}_{2} \mathrm{O}_{3}, \mathrm{Fe}_{2} \mathrm{O}_{3}, \mathrm{TiO}_{2}, \mathrm{P}_{2} \mathrm{O}_{5}$ e $\mathrm{K}_{2} \mathrm{O}$ obtidos pelo ataque sulfúrico na TFSA, índices Ki e Kr e a mineralogia da fração argila tratada com DCB, de solos da Microbacia do Córrego do Desidério

\begin{tabular}{|c|c|c|c|c|c|c|c|c|c|c|c|c|c|}
\hline Hor. & Prof. & $\mathrm{SiO}_{2}$ & $\mathrm{Al}_{2} \mathrm{O}_{3}$ & $\mathrm{Fe}_{2} \mathrm{O}_{3}$ & $\mathrm{TiO}_{2}$ & $\mathbf{P}_{2} \mathbf{O}_{5}$ & $\mathbf{K}_{2} \mathbf{O}$ & $\mathbf{K i}$ & $\mathbf{K r}$ & $\mathrm{Fe}_{\mathrm{o}}$ & $\mathrm{Fe}_{\mathrm{d}}$ & $\mathrm{Fe}_{\mathrm{o}} / \mathrm{Fe}_{\mathrm{d}}$ & $\begin{array}{c}\text { Mineralogia - argila } \\
\operatorname{DCB}^{(1)}\end{array}$ \\
\hline & $\mathrm{cm}$ & $\underline{-1}$ & 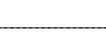 & $\%$ & 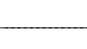 & 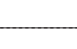 & - & & & \multicolumn{3}{|c|}{ - dag kg $\mathrm{kg}^{-1} \ldots$} & \\
\hline \multicolumn{14}{|c|}{ P1 - Latossolo Vermelho-Amarelo distrófico típico (LVAd) } \\
\hline A & $0-5$ & 5,51 & 11,43 & 7,48 & 0,98 & 0,28 & 0,02 & 0,82 & 0,58 & 3,5 & 97,47 & 0,036 & $\mathrm{Ct}>\mathrm{Gb}$ \\
\hline $\mathrm{A}$ & $0-23$ & 6,92 & 15,28 & 10,11 & 1,11 & 0,22 & 0,02 & 0,77 & 0,54 & 4,2 & 97,19 & 0,043 & $\mathrm{Ct}>\mathrm{Gb}$ \\
\hline Bw & $100-110$ & 10,11 & 23,59 & 14,07 & 1,42 & 0,28 & 0,04 & 0,73 & 0,53 & 3,13 & 101,95 & 0,031 & $\mathrm{Ct}>\mathrm{Gb}$ \\
\hline \multicolumn{14}{|c|}{ P2 - Cambissolo Háplico Tb distrófico argissólico (CXbd) } \\
\hline Ap & $0-5$ & 11,85 & 11,24 & 8,8 & 1,6 & 0,35 & 0,16 & 1,79 & 1,2 & 7,29 & 107,29 & 0,068 & $\mathrm{Ct}>\mathrm{Gb}$; traços $\mathrm{Il}$ \\
\hline $\mathrm{A}$ & $0-20$ & 12,59 & 12,72 & 7,73 & 1,36 & 0,31 & 0,18 & 1,68 & 1,21 & 6,2 & 89,14 & 0,07 & $\mathrm{Ct}>\mathrm{Gb}$; traços Il \\
\hline $\mathrm{Bi}$ & $37-70$ & 12,59 & 15,19 & 8,87 & 1,52 & 0,22 & 0,15 & 1,41 & 1,03 & 6,37 & 100,19 & 0,064 & $\mathrm{Ct}>\mathrm{Gb}$ \\
\hline $2 \mathrm{~A} / 2 \mathrm{Bi}_{1}$ & $85-100$ & 11,24 & 14,92 & 8,6 & 1,61 & 0,35 & 0,14 & 1,28 & 0,94 & 5,86 & 99,04 & 0,059 & $\mathrm{Ct}>\mathrm{Gb}$ \\
\hline $2 \mathrm{Bi}_{2}$ & $114-134$ & 11,73 & 15,24 & 8,66 & 1,5 & 0,37 & 0,13 & 1,31 & 0,96 & 4,2 & 116,4 & 0,036 & \\
\hline \multicolumn{14}{|c|}{ P3 - Cambissolo Háplico Tb distrófico argissólico (CXbd) } \\
\hline Ap & $0-17$ & 7,84 & 10,44 & 10,21 & 1,41 & 0,59 & 0,35 & 1,28 & 0,79 & 9,87 & 91,31 & 0,108 & $\mathrm{Ct}>\mathrm{Gb} ;$ traços Il \\
\hline $\mathrm{AB}$ & $17-35$ & 5,63 & 7,82 & 7,5 & 1,51 & 0,38 & 0,42 & 1,22 & 0,76 & 13,03 & 101,44 & 0,128 & $\mathrm{Ct}>\mathrm{Il}>\mathrm{Gb}$; traços VHE? \\
\hline $2 \mathrm{~A}$ & $35-44$ & 6,43 & 7,51 & 9,19 & 1,34 & 0,41 & 0,41 & 1,46 & 0,82 & 11,88 & 114,95 & 0,103 & $\mathrm{Ct}>\mathrm{Gb}$ \\
\hline $2 \mathrm{Bi}$ & $44-80^{+}$ & 8,31 & 11,68 & 8,81 & 1,72 & 0,45 & 0,52 & 1,21 & 0,82 & 9,84 & 121,86 & 0,081 & $\mathrm{Ct}>\mathrm{Il}>\mathrm{Gb}$ \\
\hline \multicolumn{14}{|c|}{ P4 - Latossolo Vermelho-Amarelo distrófico típico (LVAd) } \\
\hline A & $0-20$ & 7,07 & 22,66 & 14,34 & 2,15 & 0,4 & 0,01 & 0,53 & 0,38 & 5,35 & 116,16 & 0,046 & $\mathrm{~Gb}>\mathrm{Ct}$ \\
\hline $\mathrm{Bw}$ & $20-90^{+}$ & 7,19 & 25 & 16,94 & 2,46 & 0,35 & 0,01 & 0,49 & 0,34 & 4,88 & 127,16 & 0,038 & $\mathrm{~Gb}>\mathrm{Ct}$ \\
\hline \multicolumn{14}{|c|}{ P5 - Cambissolo Háplico Tb distrófico argissólico (CXbd) } \\
\hline A & $0-20$ & 13,51 & 20,23 & 8,01 & 1,13 & 0,35 & 0,28 & 1,13 & 0,91 & 4,46 & 41,19 & 0,108 & \\
\hline $\mathrm{Bi}$ & $25-65$ & 14,78 & 24,67 & 9,15 & 1,34 & 0,37 & 0,3 & 1,02 & 0,82 & 3,86 & 63,31 & 0,061 & \\
\hline $\mathrm{CR}$ & $160^{+}$ & 17,43 & 31,54 & 30,32 & 6,15 & 0,64 & 1,21 & 0,94 & 0,58 & & & & \\
\hline \multicolumn{14}{|c|}{ P6 - Argissolo Vermelho-Amarelo distrófico latossólico (PVAd) } \\
\hline Ap & $0-15$ & 15,13 & 17,85 & 8,37 & 1,22 & 0,39 & 0,17 & 1,44 & 1,11 & 6,46 & 55,98 & 0,115 & $\mathrm{Ct}>\mathrm{Gb}($ traços $)$ \\
\hline $\mathrm{AB}$ & $15-25$ & 15,59 & 20,06 & 9,06 & 1,23 & 0,42 & 0,19 & 1,32 & 1,03 & 6,01 & 52,62 & 0,114 & $\mathrm{Ct}>\mathrm{Gb}$ \\
\hline $\mathrm{Bt}_{1}$ & $25-42$ & 15,16 & 21,24 & 9,8 & 1,16 & 0,37 & 0,19 & 1,21 & 0,94 & 6,42 & 66,48 & 0,097 & $\mathrm{Ct}>\mathrm{Gb}($ traços $)$ \\
\hline $\mathrm{Bt}_{2}$ & $42-85$ & 15,44 & 21,64 & 10,27 & 1,49 & 0,36 & 0,21 & 1,21 & 0,93 & 9,44 & 77,64 & 0,122 & $\mathrm{Ct}>\mathrm{Gb}$ (traços) \\
\hline $\mathrm{Bt}_{3}$ & $85-120$ & 18,5 & 26,27 & 12,06 & 1,55 & 0,42 & 0,28 & 1,2 & 0,93 & 5,64 & 89,54 & 0,063 & $\mathrm{Ct}>\mathrm{Gb}$ \\
\hline $\mathrm{BC}$ & $120-150^{+}$ & 14,61 & 21,03 & 9,45 & 2,05 & 0,56 & 0,55 & 1,18 & 0,92 & 7,2 & 112,75 & 0,064 & $\mathrm{Ct}>\mathrm{Gb}$ \\
\hline
\end{tabular}

(1) $\mathrm{Ct}$ : caulinita; Gb: gibbsita; Il: ilita; VHE: vermiculita hidroxi entrecamadas.

proporcionou enriquecimento em bases e micronutrientes, assim como elevados teores de $\mathrm{K}$ nos horizontes superficiais nos solos (Quadro 2).

\section{Aspectos micromorfológicos}

Foi feita, em todas as lâminas, uma descrição sucinta da microestrutura, feições pedológicas e identificação de grãos minerais, complementada por análises em MEV/EDS de áreas representativas em secções finas de alguns horizontes selecionados. Visando simplificar a apresentação, foram incluídos apenas os horizontes $\mathrm{Bw}$ dos Latossolos do $\mathrm{P} 1$ e P4 e dos horizontes Ap, 2A (enterrado)/2Bi1 e 2Bi2, do P2. Esse procedimento teve por objetivo contrastar os materiais mais rejuvenescidos e ricos em reserva mineral (P2) com solos mais gibbsíticos e oxídicos (P1 e P4), pobres em minerais primários, à exceção do quartzo.

\section{Micropedologia dos Latossolos mais oxídicos (P1 e P4) nas duas sequências}

$\mathrm{Na}$ figura 1a,b, ilustra-se a microestrutura granular do horizonte $\mathrm{Bw}$ do $\mathrm{P} 1$, com a parte superior (A) mais rica em matéria orgânica, e a parte inferior e avermelhada (B), com plasma amarelo-avermelhado, mais coalescida. A microestrutura granular forte, típica dos Latossolos, com agregados entre 100 e 350 $\mathrm{mm}$ dominantes, é bem evidenciada (Figura 1c), 

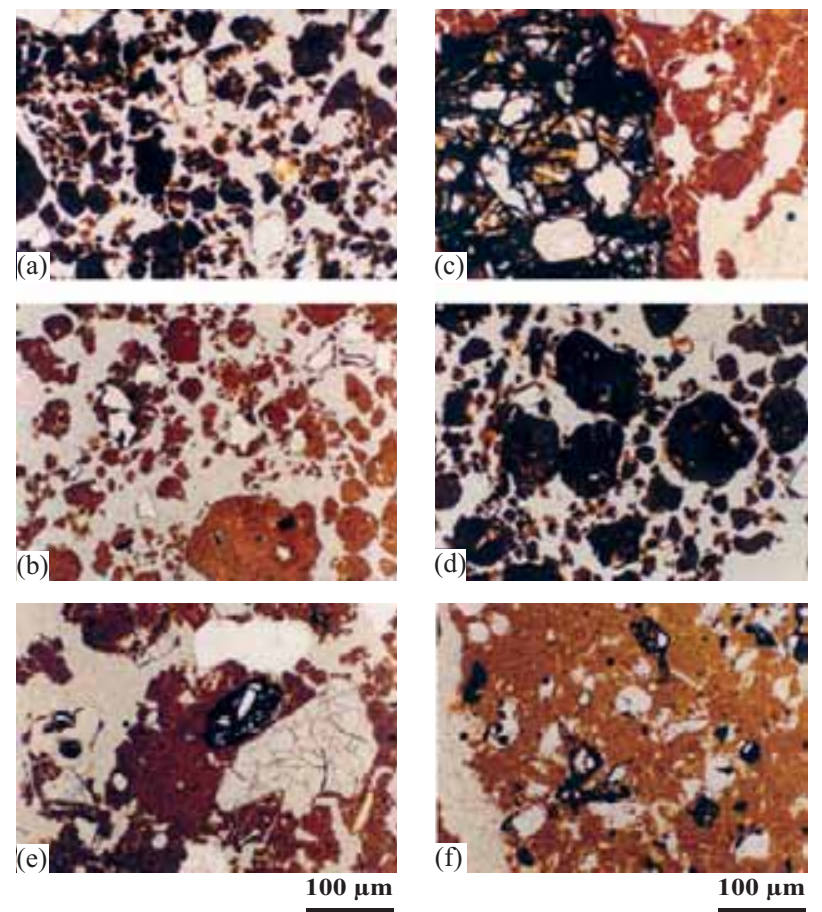

Figura 1. Fotomicrografias em luz normal de feições observadas em secções finas dos horizontes Bw dos perfis P1 (a, b) e P4 (c, d, e, f).

apresentando abundante porosidade, e poros bem conectados, à semelhança dos LVA estudados na Zona da Mata de Minas Gerais (Schaefer, 1995; Nunes et al., 2001; Schaefer, 2001). Como ilustrado na figura 1B, ocorrem raras litorrelíquias ferruginizadas (alteromorfos) (Delvigne, 1998) de minerais máficos em completa substituição pseudomórfica em meio ao plasma argiloso, semelhantes aos descritos em LVA da Amazônia por Andrade et al. (1997).

No horizonte Bw (100-110 cm) do LVA (P1), as fotomicrografias de retroespalhamento eletrônico em MEV revelam abundante esqueleto quartzoso em meio à microestrutura granular típica e plasma de composição caulinítica/oxídica (Figura 2a), evidenciado pelas análises por EDS, que indicaram valores de $\mathrm{Al}_{2} \mathrm{O}_{3}$ de 33,6\%, com teores de sílica maiores que os do outro Latossolo (P4) (Quadro 4). Os teores de $\mathrm{K}_{2} \mathrm{O}$ são baixos, mas superiores aos valores encontrados por Schaefer (2001) para diversos agregados de Latossolos brasileiros. Como pode ser visto pelos mapas das emissões de raios X para alguns elementos selecionados, existem grãos residuais de feldspato potássico (Figura 2a,c), constituindo uma relativa reserva nãotrocável nesses solos.

A natureza relativamente rica em máficos é ilustrada pela presença de abundantes alteromorfos de anfibólio completamente substituídos por óxidos de $\mathrm{Fe}$, com presença de fraturas em grãos de quartzo, contidos em agregados maiores, conforme investigado no MEV/EDS (Figura 2b, d). Os valores de $\mathrm{Fe}_{2} \mathrm{O}_{3}, \mathrm{Al}_{2} \mathrm{O}_{3}$ e $\mathrm{SiO}_{2}$ em $2 \mathrm{~d}$ e a presença de pseudomorfos de caulinita substituindo biotita (Figura 2b, Quadro 4) mostram o profundo processo de intemperismo desses minerais máficos. A "rede" de vazios e litoporos indica avançado estado de alteração desses grãos minerais (Delvigne, 1998; Lacerda et al., 2001).

O plasma típico microagregado do P1 (Figura 2a) mostrou composição oxídica, com valores de sílica maiores que os do Latossolo do P4, corroborando a mineralogia caulinítica/oxídica evidenciada pela difratometria de raios X (Quadro 3). A microestrutura granular, revelada pela microscopia óptica e pelo retroespalhamento eletrônico, é bem evidente. Análises de raras partículas de pseudomorfos (Figura 2b, d) revelam alteromorfos completamente caulinizados em $2 \mathrm{~B}$, ao lado de micas degradadas, com maiores teores de potássio (Figura 2c), e menos ferruginizadas. Pela ocorrência incomum, é pouco provável que essas partículas micáceas representem reserva de $\mathrm{K}$ para formas mais lábeis, mas sua presença explica os teores maiores de $\mathrm{K}_{2} \mathrm{O}$ verificados pelo ataque sulfúrico (Quadro 3), corroborando os dados reportados por Melo et al. (2002) em minerais de argila de Latossolos brasileiros.
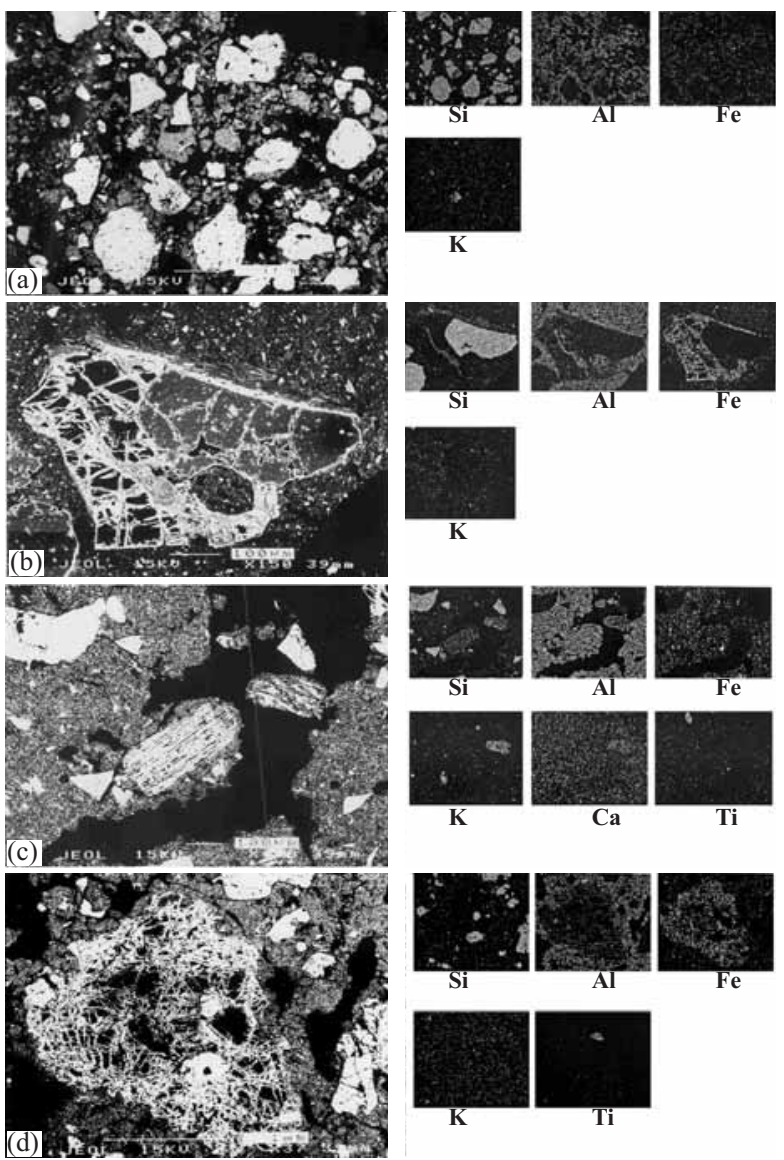

Figura 2. Fotomicrografias em MEV ("retroespalhamento eletrônico") e mapas da emissão de raios $\mathrm{X}$ de elementos selecionados, do horizonte Bw do perfil 1. 
Quadro 4. Teores de alguns elementos, obtidos por meio de análises pontuais de raios X de áreas selecionadas nas secções finas dos perfis P1 e P4

\begin{tabular}{|c|c|c|c|c|c|c|c|c|c|c|c|}
\hline Amostra & $\mathrm{MgO}$ & $\mathrm{Al}_{2} \mathrm{O}_{3}$ & $\mathrm{SiO}_{2}$ & $\mathbf{P}_{2} \mathbf{O}_{5}$ & $\mathbf{K}_{2} \mathbf{O}$ & $\mathrm{CaO}$ & $\mathrm{TiO}_{2}$ & $\mathrm{MnO}_{2}$ & $\mathrm{Fe}_{2} \mathrm{O}_{3}$ & $\mathrm{CuO}$ & $\mathrm{ZnO}$ \\
\hline & \multicolumn{11}{|c|}{$\mathrm{LVA}-(\mathrm{P} 1) \mathrm{Bw}$} \\
\hline $2 \mathrm{~A}-$ plasma & 0,13 & 33,60 & 19,03 & - & 0,13 & 0,11 & 0,98 & & 15,98 & 0,04 & 0,36 \\
\hline $2 \mathrm{~A}$ - Grão de feldspato & 0,15 & 12,11 & 40,47 & & 21,56 & 0,03 & 0,23 & 0,06 & 0,12 & 0,23 & 0,34 \\
\hline 2B - pseudomorfo de caulinita & 0,15 & 27,13 & 34,12 & & 0,20 & & 0,22 & & 8,56 & 0,28 & 0,04 \\
\hline $2 \mathrm{C}-$ mica degradada & 0,14 & 12,74 & 43,39 & 0,19 & 22,96 & 0,03 & 0,30 & 0,11 & 0,09 & 0,13 & 0,14 \\
\hline \multirow[t]{2}{*}{$2 \mathrm{D}$ - alteromorfo de anfibólio } & 0,24 & 8,64 & 2,07 & 0,44 & 0 & 0 & 1,25 & 0,12 & 61,12 & & \\
\hline & \multicolumn{11}{|c|}{$\mathrm{LVA}-(\mathrm{P} 4) \mathrm{Bw}$} \\
\hline 3A plasma & 0,68 & 32,59 & 12,92 & 0,10 & 0,1 & 0,04 & 2,07 & 0,02 & 22,8 & 0,21 & \\
\hline 3A nódulo de gibbsita & 0,44 & 54,22 & 7,05 & 0,13 & & 0,1 & 0,59 & & 7,8 & & 0,23 \\
\hline 3B grão de ilmenita & 0,3 & 0,13 & 0,05 & & 0,09 & & 44,99 & 1,39 & 53,22 & 0,16 & 0,06 \\
\hline
\end{tabular}

Imagens de retroespalhamento eletrônico (MEV) permitem observar a microestrutura granular forte, relacionada à atividade pedobiológica no horizonte $\mathrm{Bw}$ do P4 (Figura 3a). Os mapas das emissões de raios X correspondentes à figura 3B (Quadro 4) e análises pontuais revelam a natureza gibbsítica do plasma, com teores totais de nutrientes muito baixos. Nódulos gibbsíticos ocorrem com alta concentração de $\mathrm{Al}_{2} \mathrm{O}_{3}$ (Figura $3 b$ ) e baixa concentração de $\mathrm{Fe}_{2} \mathrm{O}_{3}$, enquanto grãos residuais de ilmenita identificados apresentam teores totais elevados de $\mathrm{TiO}_{2}$ e $\mathrm{Fe}_{2} \mathrm{O}_{3}$ (Quadro 4).

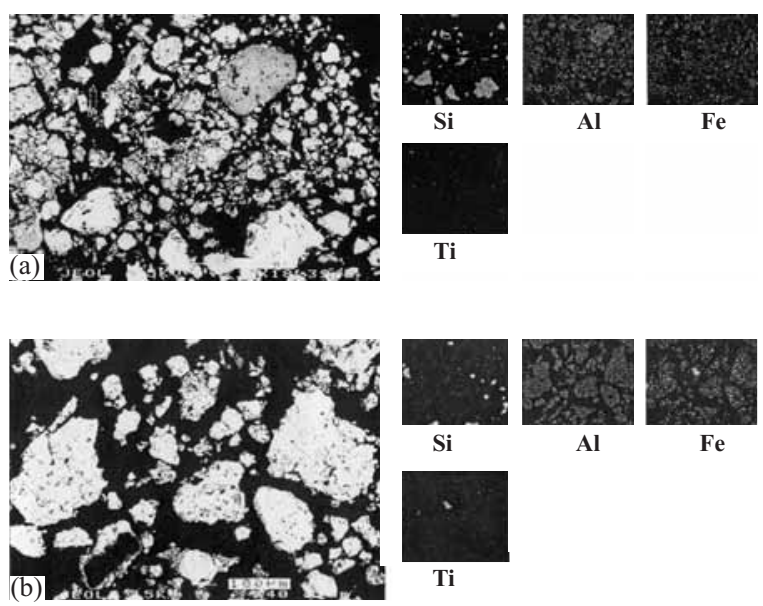

Figura 3. Fotomicrografias em MEV ("retroespalhamento eletrônico") e mapas da emissão de raios $\mathrm{X}$ de elementos selecionados, do horizonte $\mathrm{Bw}_{1}$ do perfil 4.

\section{Micropedologia do Cambissolo (perfil P2)}

No perfil P2, a microestrutura é semelhante à dos Latossolos (P1 e P4) (Figura 4), com agregados de origem pedobiológica (Figura $4 \mathrm{a}, \mathrm{b}$ ), abundante porosidade e presença de agregados maiores (Figura 4c, d), contendo grãos de quartzo, fragmentos de carvão, minerais de titânio e micronódulos de hematita (Figura 4d).

No horizonte Ap ocorrem microagregados de maior tamanho e blocos pequenos, dada a intensa atividade biológica e o aporte de matéria orgânica no solo sob bananeira (Figura 4e, f). Nesses agregados, ocorrem abundantes grãos de anfibólio e micas, com fragmentos lignificados de tecidos de pseudocaule de bananeira, impregnados com pontuações ferruginosas.

No horizonte $2 \mathrm{~A}$ enterrado, os agregados organominerais são menores, do tipo latossólico, contendo, porém, abundante reserva de minerais primários, como biotita e anfibólio, em diferentes estádios de degradação (Figura 4a, b). Abaixo desse horizonte ocorre uma zona mais latossólica e avermelhada (2Bi1), com alguns grãos de feldspato e micas (Figura 4b, d), associados a abundantes fragmentos de carvão. No horizonte $2 \mathrm{Bi} 2$, na base do perfil, a microestrutura latossólica é evidente, com presença de canais biológicos, partículas minerais alteradas, como micas (Figura 4g), e abundantes grãos de quartzo (Figura 4h). Há, portanto, enriquecimento mineral por pedoturbação em materiais provenientes dos afloramentos de rocha a montante.

As feições pedológicas observadas em retroespalhamento eletrônico no MEV e os mapas de emissões de raios $\mathrm{X}$ do horizonte Ap ilustram uma estrutura 

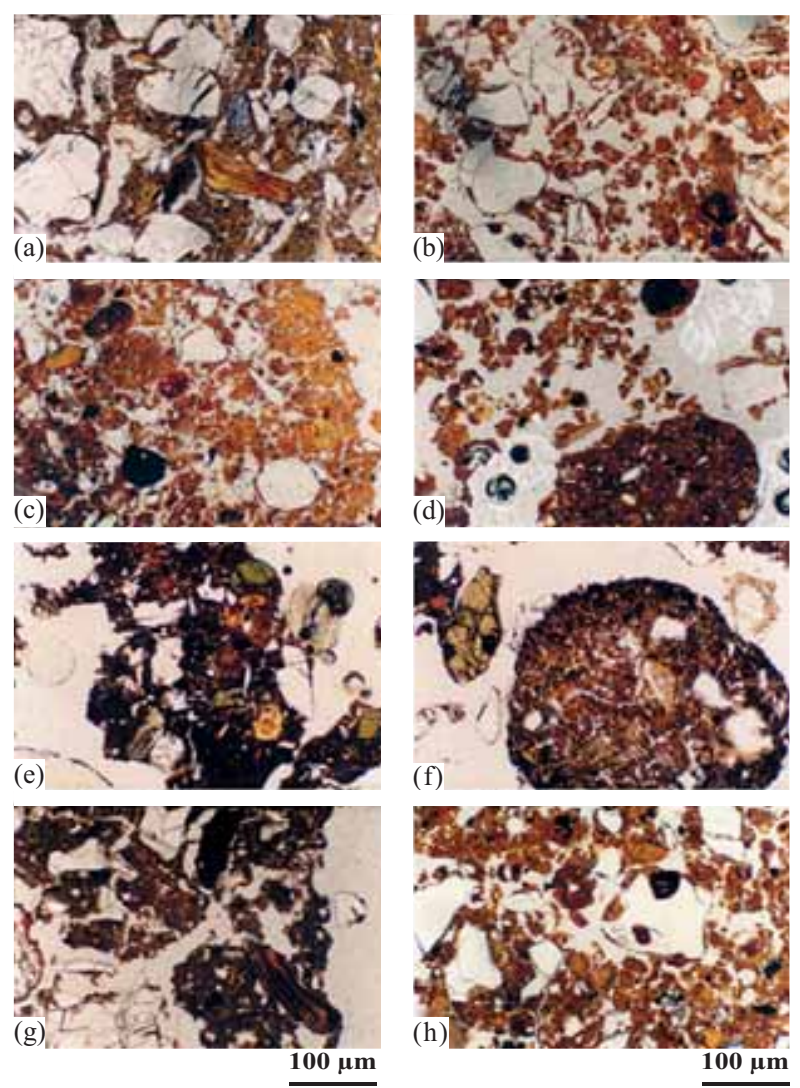

Figura 4. Fotomicrografias em luz normal de feições observadas em secções finas dos horizontes Ap $(e, f), 2 \mathrm{~A} / 2 \mathrm{Bi} i_{1}(\mathrm{a}, \mathrm{b}, \mathrm{c}, \mathrm{d})$ e $2 \mathrm{Bi}_{2}(\mathrm{~g}, \mathrm{~h})$ do perfil 2.

em blocos pequenos, com presença de grãos de quartzo (entre 300 e $1.000 \mu \mathrm{m})$ e grãos comuns de feldspatos potássicos $(<300 \mu \mathrm{m})$. Microagregados de origem pedobiológica (Figura 5a) incluem grãos subarredondados de quartzo, feldspato ( $200 \mu \mathrm{m}$, com $21,9 \% \mathrm{~K}_{2} \mathrm{O}$ - Quadro 5) e nódulo aluminoso (zona mais clara). Os agregados em bloco (Figura 5b, c) são constituídos de plasma argiloso com inclusões de quartzo, nódulos de $\mathrm{Fe} / \mathrm{Al}$, plagioclásios de $\mathrm{Na}$ e Ca, feldspato potássico, micas degradadas e minerais de Ti, mostrando expressiva heterogeneidade mineralógica.

Outros autores descreveram a presença de grãos minerais primários em solos ferralíticos (Verheye \& Stoops, 1975; Baert \& van Ranst, 1997), mas questionaram sua validade como critério distintivo de horizontes óxicos (latossólicos) ou câmbicos. Smith (1986) acredita que não exista real potencial de liberação de nutrientes com 10 \% de grãos primários; contudo, em escala de pequena produção agrícola, a presença de minerais primários e caráter câmbico parece ser muito importante para ser negligenciada.

No horizonte $2 \mathrm{~A}$ enterrado é grande a diversidade da reserva mineralógica. A figura 6 a mostra microagregado com aproximadamente $0,8 \mathrm{~mm}$ de diâmetro, contendo grãos de quartzo, pseudomorfos de mica transformados em gibbsita $\left(67 \% \mathrm{Al}_{2} \mathrm{O}_{3}\right)$, localmente ferruginizados, grãos de feldspato potássico menores que $100 \mu \mathrm{m}$ e grãos minerais de Ti. Neste horizonte ocorrem microagregados ovóides, provavelmente de origem biológica (Delvigne, 1998), contendo grãos de feldspato potássico, quartzo, minerais de Ti e minerais de anfibólio parcialmente alterados, intemperizando isovolumetricamente em óxidos de $\mathrm{Fe}$ (forte retroespalhamento eletrônico) (Figura 6b). Entre essas inclusões nos microagregados são comuns grãos de feldspato potássico $(\sim 20 \mu \mathrm{m}) \mathrm{e}$ grãos de plagioclásio sódico, conforme se observa à direita na figura 6c e no mapa de emissão de raios $\mathrm{X}$ (Quadro 5), que indica $\mathrm{Na}>\mathrm{Ca}$. $\mathrm{Na}$ borda de microagregados, a reserva mineral é ilustrada na figura 6D e no mapa de emissão de raios X (Quadro 5), com litorrelíquias de biotita pouco alteradas, grãos de feldspato e quartzo.

No horizonte 2A ocorrem ainda microagregados granulares, típicos de Latossolos com presença de plasma argiloso (Figura 6e), grãos de quartzo menores que $1 \mathrm{~mm}$, ilmenita e feldspato potássico (ver detalhe do grão incluído em microagregado em $6 \mathrm{~g}$ ). A parte externa dos microagregados (Figura 6f, detalhe) contém minerais primários, como feldspatos, degradados ao longo da clivagem, e anfibólio (altos teores de $\mathrm{Fe}_{2} \mathrm{O}_{3}$ e $\mathrm{CaO}$ ) (Quadro 5).
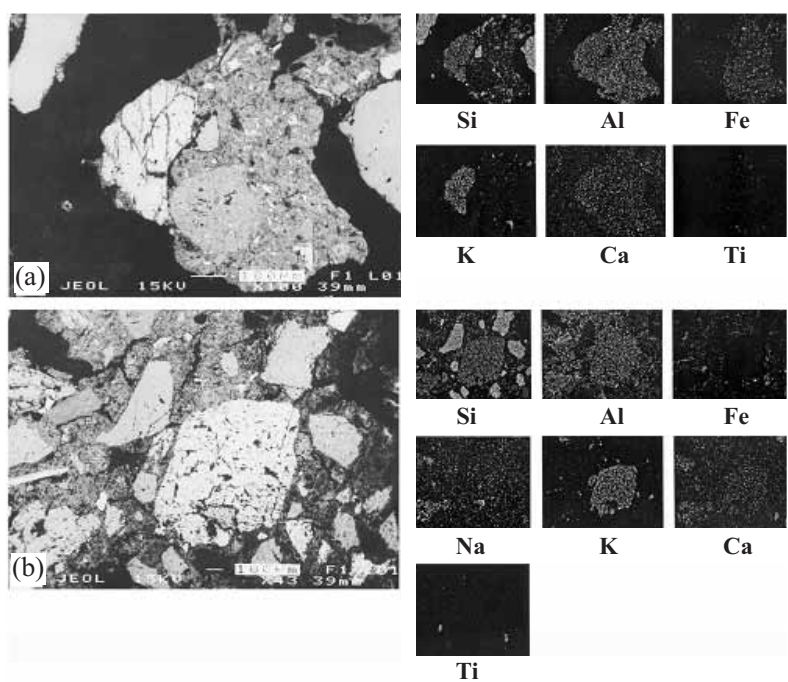

$\mathrm{Fe}$

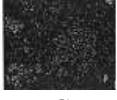

K

$\mathrm{Ca}$
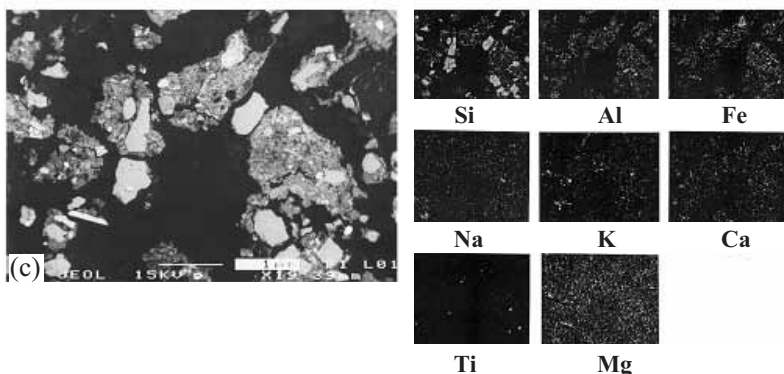

$\mathrm{Fe}$

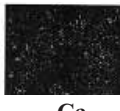

Ca

Ti

$\mathrm{Mg}$

Figura 5. Fotomicrografias em MEV ("retroespalhamento eletrônico") e mapas da emissão de raios $\mathrm{X}$ de elementos selecionados, do horizonte Ap do perfil 2. 
Quadro 5. Mapas microquímicos de áreas selecionadas nas secções finas dos horizontes Ap, 2A enterrado/ $2 \mathrm{Bi}_{1}$ e $2 \mathrm{Bi}_{2}$ enterrado do perfil $\mathrm{P2}$

\begin{tabular}{|c|c|c|c|c|c|c|c|c|c|c|c|}
\hline Amostra & $\mathrm{MgO}$ & $\mathrm{Al}_{2} \mathrm{O}_{3}$ & $\mathrm{SiO}_{2}$ & $\mathbf{P}_{2} \mathbf{O}_{5}$ & $\mathbf{K}_{2} \mathbf{O}$ & $\mathrm{CaO}$ & $\mathrm{TiO}_{2}$ & $\mathrm{MnO}_{2}$ & $\mathrm{Fe}_{2} \mathrm{O}_{3}$ & $\mathrm{CuO}$ & $\mathrm{ZnO}$ \\
\hline \multirow{3}{*}{$5 \mathrm{~A}-\mathrm{K}$-feldspsto degradado } & \multicolumn{11}{|c|}{$\mathrm{CXbd}-(\mathrm{P} 2) \mathrm{Ap}$} \\
\hline & 0,1 & 12,02 & 40,93 & & 21,84 & 0 & 0,2 & 0,14 & & 0,18 & 0,22 \\
\hline & \multicolumn{11}{|c|}{$\mathrm{CXbd}-(\mathrm{P} 2) \quad 2 \mathrm{~A} / 2 \mathrm{Bi}_{1}$} \\
\hline $6 \mathrm{~A}-$ gibbsita pseudomorfa & 0,39 & 66,96 & 0,57 & 0,05 & 0,11 & 0,05 & 0,02 & 0 & 0,32 & 0,07 & \\
\hline $6 \mathrm{D}$ - biotita inalterada & 0,27 & 12,82 & 27,11 & 0 & 7,71 & 0,54 & 4,73 & 0,61 & 45,33 & 0 & 0,16 \\
\hline $6 \mathrm{E}-$ plasma agreg. típico & 0,26 & 25 & 22,11 & 0,16 & 0,12 & 0,41 & 1,51 & 0 & 19,7 & 0,25 & 0,05 \\
\hline $9 \mathrm{~F}$ - anfibólio & 0,86 & 60,7 & 22,24 & & 2,29 & 9,97 & 1,25 & 0,6 & 31,1 & & 0,3 \\
\hline $6 \mathrm{~F}$ - grão K-feldspato & 0,14 & 12,11 & 41,1 & & 21,85 & 0 & 0,18 & 0,08 & 0,12 & & \\
\hline \multirow[t]{2}{*}{$6 \mathrm{H}$ - grão ilmenita } & 0 & 0 & 0,04 & 0 & 0,16 & 0,05 & 45,49 & 1,99 & 53,22 & 0,22 & \\
\hline & \multicolumn{11}{|c|}{$\mathrm{CXbd}-(\mathrm{P} 2) 2 \mathrm{Bi}_{2}$} \\
\hline 7A - plasma típico & 0,33 & 28,89 & 27,63 & 0 & 0,26 & 0,11 & 1,24 & 0 & 13,33 & 0 & 0 \\
\hline 7B - grão gibbsita - centro & 0,12 & 70,39 & 0,27 & 0,09 & 0,09 & & & 0,27 & 1,49 & & \\
\hline
\end{tabular}
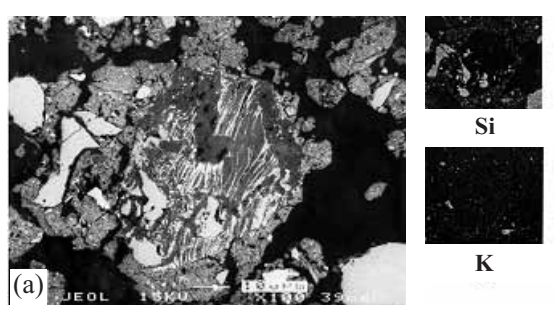

$\mathbf{K}$
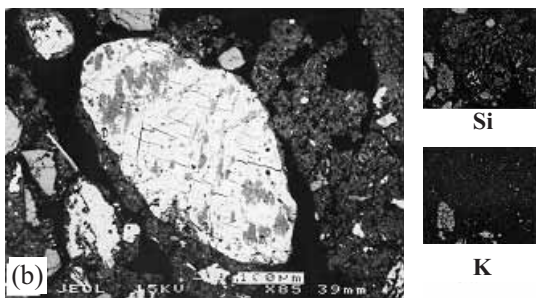

$\mathbf{K}$
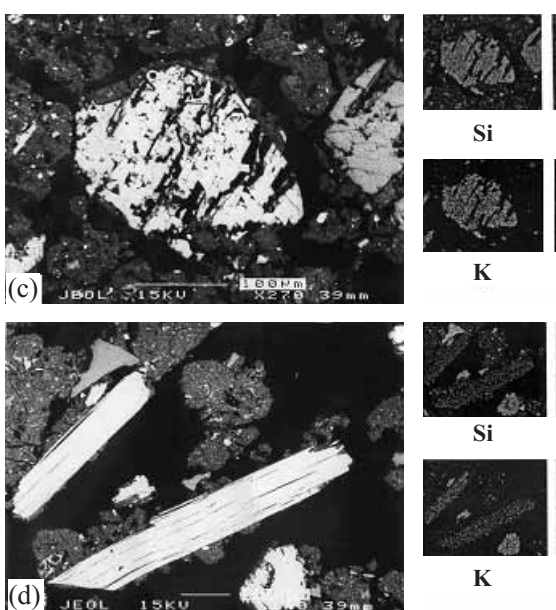

$\mathbf{K}$

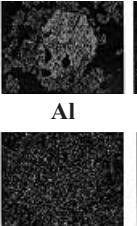

Ca

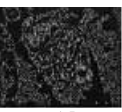

Al

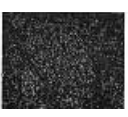

Ca

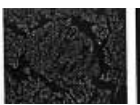

Al

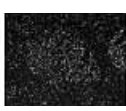

Ca
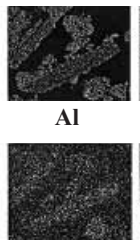

$\mathrm{Ca}$

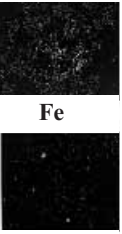

Ti
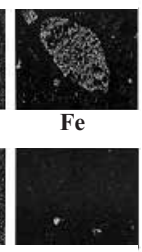

Ti

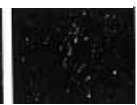

$\mathrm{Fe}$

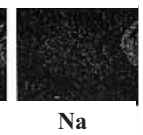

Na
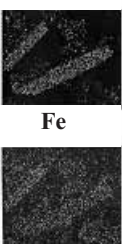

Ti

No horizonte 2Bi (Figura 7) observa-se, também, a microestrutura granular típica, com abundante esqueleto grosseiro de quartzo e feldspato potássico (areia fina, com grãos menores que $300 \mu \mathrm{m}$ ) e grãos residuais de $\mathrm{Ti} / \mathrm{Fe}$, imersos em plasma caulinítico/
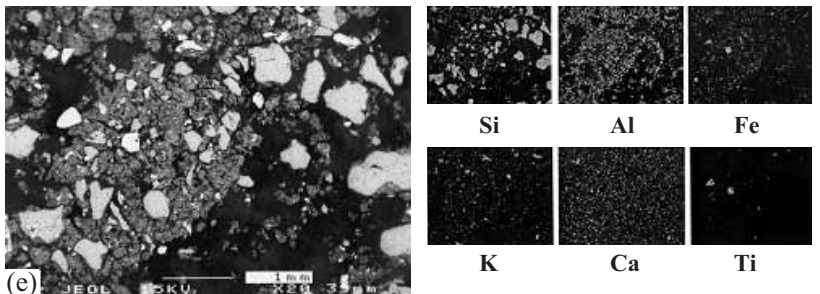

Fe
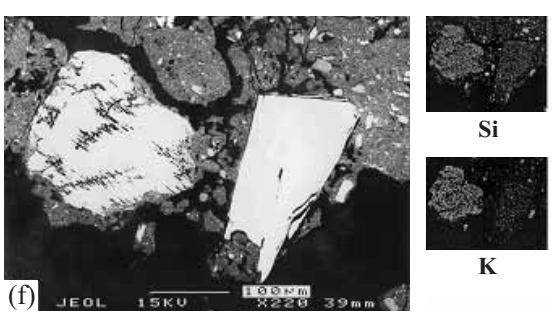

$\mathrm{Ca}$
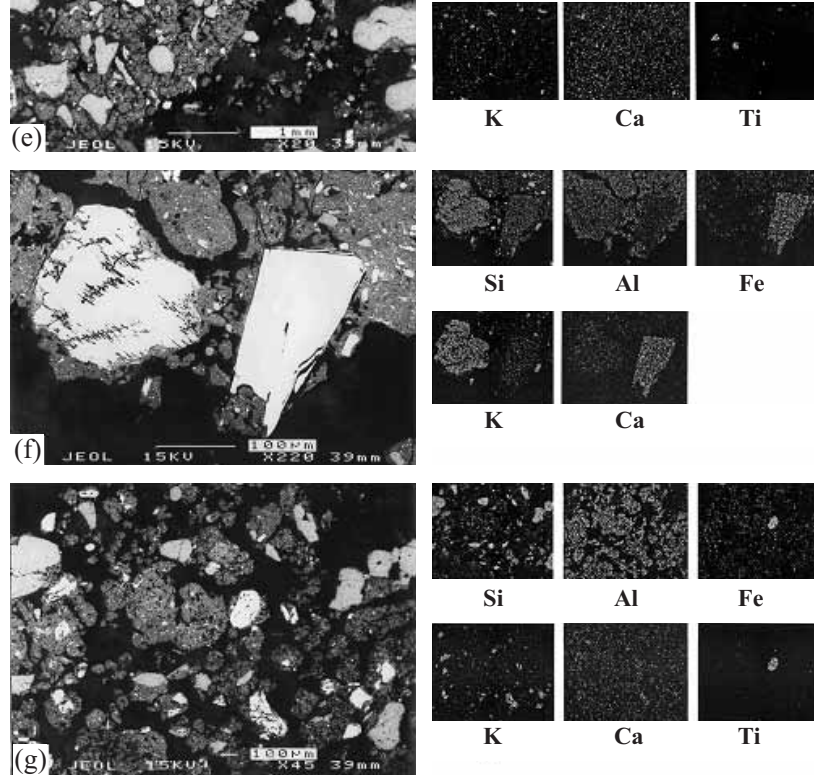

Al

Fe

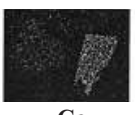

Ca
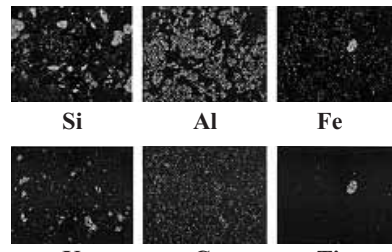

Al

$\mathrm{Fe}$

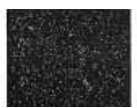

$\mathrm{K} \quad \mathrm{Ca}$

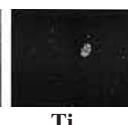

Figura 6. Fotomicrografias em MEV ("retroespalhamento eletrônico") e mapas da emissão de raios X de elementos selecionados, do horizonte $2 A$ (enterrado) do perfil 2. 


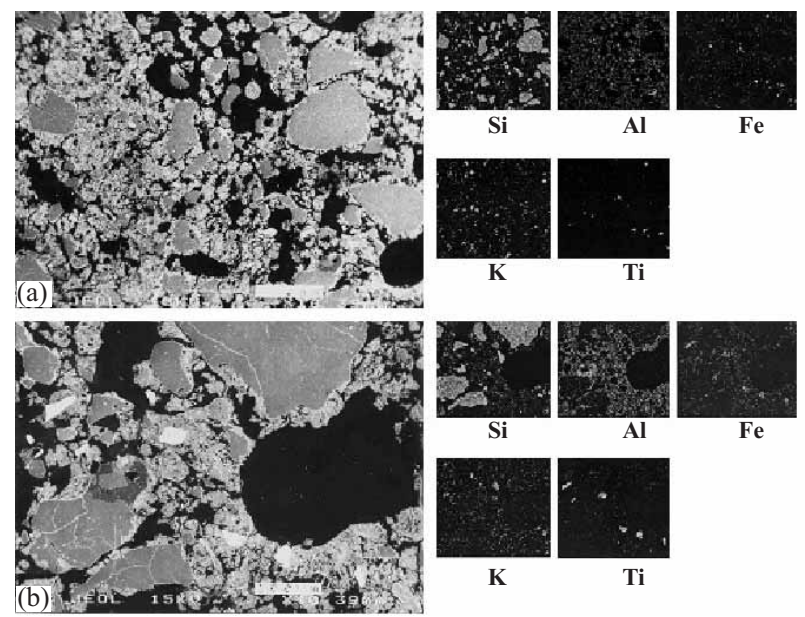

Figura 7. Fotomicrografias em MEV ("retroespalhamento eletrônico") e mapas da emissão de raios $X$ de elementos selecionados, do horizonte $2 \mathrm{Bi}_{1}$ do perfil 2.

oxídico (Quadro 5-Figura 7a). A atividade biológica é intensa, com canais biológicos (formas semicirculares - Figura 7b) que aparecem como zona de mais baixo retroespalhamento do plasma argiloso, mais gibbsitizados, titano-ferruginosos, com grãos de quartzo e feldspato potássico na areia grossa.

\section{CONCLUSÕES}

1. Nas partes mais elevadas da região de Governador Valadares, os solos exibem morfologia latossólica e uma mineralogia goethítica/gibbsítica, indicando o alto grau de intemperismo no local onde os solos se desenvolveram. Nas partes côncavas e rejuvenescidas, há mistura de materiais préintemperizados (latossólicos), de natureza coluvial, com abundantes grãos de minerais primários de aporte recente, relacionados aos de núcleos rochosos aflorantes, a montante, conferindo o caráter câmbico aos solos. Esses Cambissolos situam-se nas áreas preferenciais de cultivo de subsistência, especialmente de bananeira, possivelmente pela maior reserva de nutrientes.

2. Estudos micromorfológicos e por microscopia eletrônica corroboram a natureza poligenética, com marcante influência da alternância da morfogênese atual e pedogênese pretérita, nas características físicas e químicas dos solos estudados, sobretudo nos Cambissolos associados às vertentes.

\section{LITERATURA CITADA}

Ab'SABER, A.N. Espaços ocupados pela expansão dos climas secos da América do Sul, por ocasião dos períodos glaciais quaternários. Inst. Geogr. Paleoclimas, 3:1-19, 1977.
ALVAREZ V., V.H.; NOVAIS, R.F.; DIAS, L.E. \& OLIVEIRA, J.A. Determinação e uso do fósforo remanescente. B. Inf. SBCS, 25:27-32, 2000.

ANDRADE, H.; SCHAEFER, C.E.R.; DEMATTE, J.L.I. \& ANDRADE, F.V. Pedogeomorfologia e micropedologia de uma sequência Latossolo - Areia Quartzosa Hidromórfica sobre rochas cristalinas do Estado do Amazonas. Geonomos, 5:55-66, 1997.

BAERT, G. \& van RANST, E. Total reserve in bases' as an alternative for weatherable mineral content in soil classification: A micromorphological investigation. In: INTERNATIONAL WORKING MEETING ON SOIL MICROMORPHOLOGY, 10., Moscow, 1997. Proceedings. Wageningen, 1997. p.41-51.

BRASIL - Ministério da Agricultura.Levantamento Exploratório dos Solos da Região sob Influência da Cia. Vale do Rio Doce. Rio de Janeiro, 1970. 154p. (Boletim Técnico, 13)

BRASIL - Ministério das Minas e Energia. Secretaria Geral. PROJETO RADAMBRASIL. Levantamento de Recursos Naturais. Folhas SD. 24. Salvador, 1981. v.24. 620p.

BRASIL - Ministério das Minas e Energia. Secretaria Geral. PROJETO RADAMBRASIL. Levantamento de Recursos Naturais, Folhas SF. 23/24. Rio de Janeiro/Vitória, 1983. v. $32.775 p$.

BRASIL - Ministério das Minas e Energia. Secretaria Geral. PROJETO RADAMBRASIL. Levantamento de Recursos Naturais, Folhas SE. 24. Rio Doce, 1987. v.34. 544p.

CASTRO, S.S. Impregnação de amostras de solo para confeç̧ão de lâmina delgada. B. Inf. SBCS, 10:44, 1985.

CPRM - Serviço Geológico do Brasil. PROJETO LESTE Mapeamento geológico e cadastramento de recursos minerais da região leste de Minas Gerais. Folha SE.23-ZB-VI (Estado de Minas Gerais). Belo Horizonte, 2000. v.1. $55 \mathrm{p}$.

DELVIGNE, J.E. Atlas of micromorphology and mineralogist. Ottawa, ORSTOM,1998. 494p.. (Special Publication, 3)

EMPRESA BRASILEIRA DE PESQUISA AGROPECUÁRIA EMBRAPA. Centro Nacional de Pesquisa de Solos. Manual de métodos de análise de solo. 2 ed. Rio de Janeiro, Centro Nacional de Pesquisa de Solos, 1997. 212p.

EMPRESA BRASILEIRA DE PESQUISA AGROPECUÁRIA EMBRAPA. Centro Nacional de Pesquisa de Solos. Sistema brasileiro de classificação de solos. Brasília, 1999. 461p.

EMPRESA BRASILEIRA DE PESQUISA AGROPECUÁRIA EMBRAPA. Serviço Nacional de Levantamento e Classificação de Solos. Estudo micropedológico e pesquisa sobre a gênese de Podzólico Vermelho-Amarelo equivalente eutrófico da região do Vale do Rio Doce Minas Gerais. Recife, 1977. 130p. (Boletim Técnico, 43)

EMPRESA BRASILEIRA DE PESQUISA AGROPECUÁRIA EMBRAPA. Serviço Nacional de Levantamento e Classificação de Solos. Manual de métodos de análise de solo. Rio de Janeiro, 1979. 216p.

FITZPATRICK, E.A. Soil microscopy and micromorphology. New York, John Wiley \& Sons, 1993. 304p. 
KING, L.C. A geomorfologia do Brasil Oriental. R. Bras. Geog., 18:147-265, 1956.

KÖPPEN, W. Climatologia. Com um estúdio de los climas dew la tierra. México, FCE, 1948. p. 482-487.

LACERDA, M.P.C.; ANDRADE, H. \& QUÉMÉNEUR, J.J.G. Micropedologia da alteração em perfis de solos com B textural na região de Lavras, Minas Gerais. R. Bras. Ci. Solo, 24:829-841, 2001.

LEMOS, R.C. \& SANTOS, R.D. Manual de descrição e coleta de solo no campo. 3.ed. Campinas, Sociedade Brasileira de Ciência do Solo, 1996. 84p.

LOPES, A.S. Solos sob "cerrado": Características, propriedades e manejo. 2.ed. Piracicaba, Associação Brasileira para Pesquisa da Potassa e Fosfato, 1984. 162p.

MEHRA, J.P. \& JACKSON, M.L. Iron oxides removal from soils and clays by a dithionite-citrate-bicarbonate system buffered with sodium bicarbonate. Clays Clay Miner., 4:317-327, 1960 .

MELO, V.F.; SCHAEFER, C.E.G.R.; NOVAIS, R.F.; SINGH, B. \& FONTES, M.P.F. Potassium and magnesium in clay minerals of some Brazilian soils as incated by a sequential extraction procedure. Comm. Soil Sci. Plant Anal., 33:22032225,2002 .

NUNES, W.A.G.A.; KER, J.C.; SCHAEFER, C.E.; FERNANDES-FILHO, E.I. \& GOMES, F.H. Relação solopaisagem-material de origem e gênese de alguns solos do Domínio do "Mar de Morros", MG. R. Bras. Ci. Solo., 25:341354, 2001.

RESENDE, M.; CURI, N.; REZENDE, S.B. \& CORRÊA, G.F. Pedologia: Base para distinção de ambientes. Viçosa, MG, NEPUT, 1995. 304p.
SAADI, A. Neotectônica da plataforma brasileira: Esboço e interpretação preliminares. Geonomos, 1:1-15, 1993.

SCHAEFER, C.E.G.R. Micropedologia de uma seqüência Latossolo-Podzólico de Viçosa, MG: Química e morfologia da superfície de agregados dos horizontes Bw e Bt. In: Anais do XXV Cong. Bras. Ci. Solo. Viçosa - MG, SBCS, 1995.

SCHAEFER, C.E.G.R. The B horizon microstructure of Brazilian Latosols as long-term biotic contructs. Austr. J. Soil Res., 39:909-926, 2001.

SCHWERTMANN, U. The differentiation of iroan oxides in soils by a photochemical extraction with acid ammonium oxalate. Mit ammoniumoxalate-lösung. Pflanzen. Dueng. Bodenkd., 105:194-201, 1964. (Abstr: Soil Fert., 28:28).

SMITH, G. Relationale for concepts in soil taxonomy. Washington, SMSS 1986. 259p. (Technical Monograph, 11)

SOUZA, C.J.O. Interpretação morfotécnica da Bacia do Rio Doce. Belo Horizonte, Universidade Federal de Minas Gerais, 1995. 146p. (Tese de Mestrado)

STOOPS, G. Relict properties in soils of humid tropical regions with special reference to Central Africa. Catena, 16:95106, 1989. Supplement.

VERHEYE, W. \& STOOPS, G. Nature and evolution of soils developed on the granite complex in the subhumid tropics (Ivory Coast). II. Micromorphology and mineralogy. Pedologie, 25:40-55, 1975.

YEOMANS, A. \& BREMNER, J.M. A rapid and precise method for routine determination of organic carbon in soil. Comm. Soil Sci. Plant Anal., 19:1467-1476, 1988. 